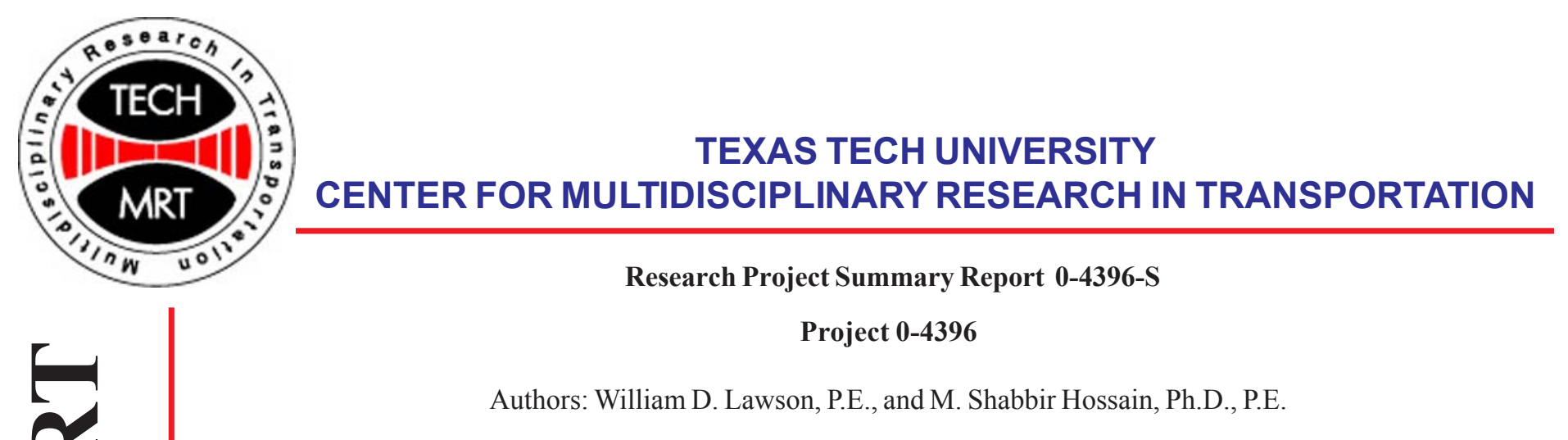

\title{
Best Practices for Pavement Edge Maintenance
}

This research addresses the problem of pavement edge dropoffs as a maintenance, safety, and liability issue for the Texas Department of Transportation (TxDOT). With impact to TxDOT's entire roadway system including more than 41,000 centerline miles of Farm-toMarket (FM) highways and millions of dollars in annual maintenance funds, the edge maintenance issue warrants that "best practices" for pavement edge maintenance be defined and implemented. This is clearly a maintenance concern, and this research is intentionally focused from the maintenance perspective.

\section{What We Did...}

Stated simply, our research objectives have been (1) to define the most effective and efficient practices for repairing and stabilizing edge failures and (2) to communicate these "best practices" through practical, clear, and effective training to TxDOT maintenance forces.

The project spanned two calendar years, September 2001 through August 2003, with the first year devoted to identifying best practices for pavement edge maintenance and the second year devoted to training for implementation of the best practices.

The work plan was comprised of seven tasks. In Task 1, we completed a literature review on the subject. Tasks 2 and 3 consisted of a survey of each of TxDOT's 25 geographic/ operational Districts to capture institutional knowledge and determine current methods, equipment and materials for pavement edge repair projects (see Figure 1). We traveled to each District where we interviewed key maintenance personnel and observed selected examples of completed edge repair projects.

In Task 4, we developed a draft pavement edge repair specification. The draft

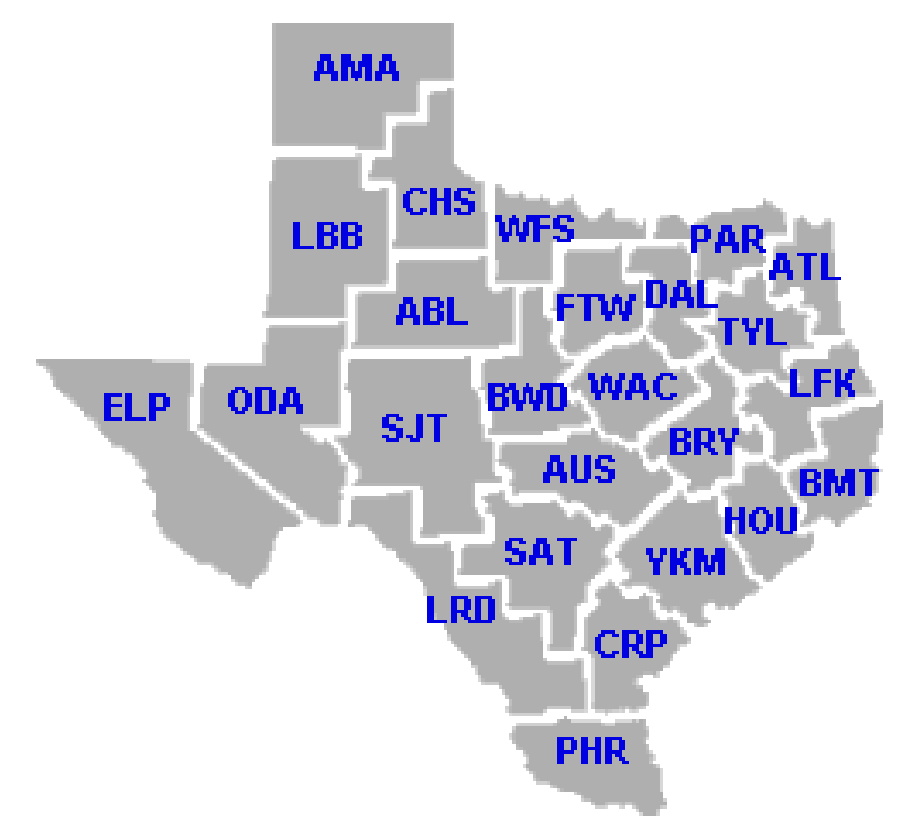

Figure 1. This research captured over 3700 years of institutional knowledge on pavement edge maintenance from all 25 TxDOT districts. 


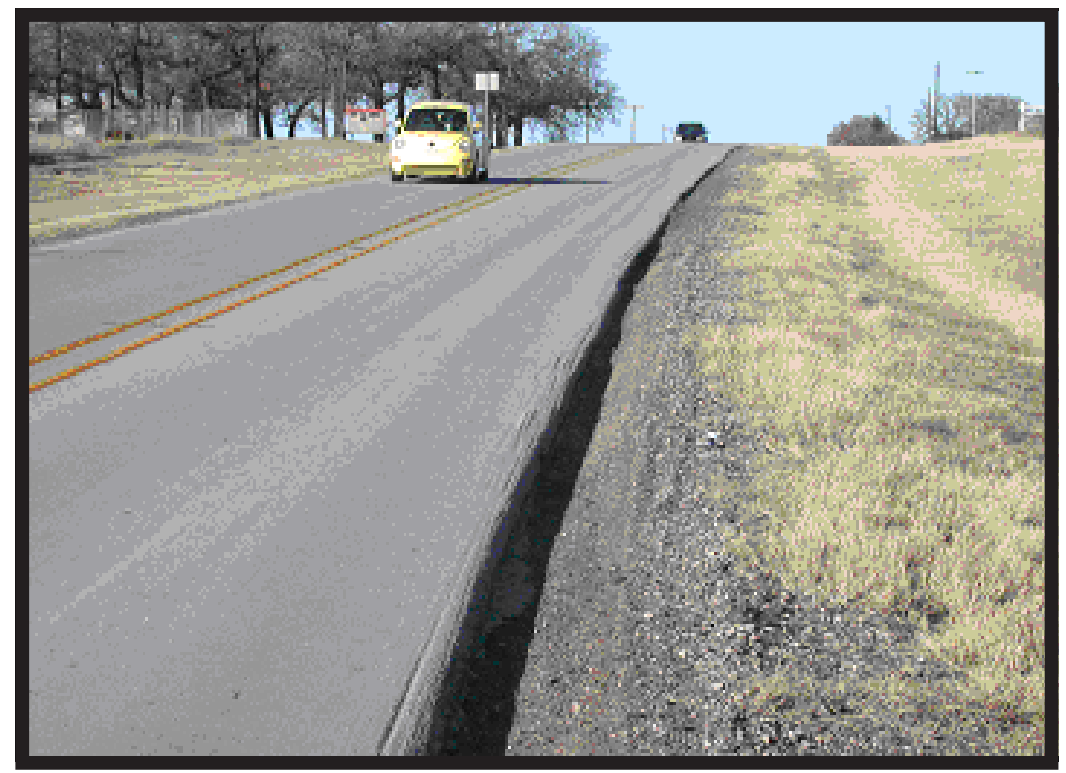

Figure 2. Maintenance personnel define edge drop-offs in risk-based terms with respect to two functional criteria: 1) the impact on safety of the traveling public, and 2) the potential for damage to the road.

specification incorporates current repair specifications, both from TxDOT and elsewhere, and contains recommendations for its application with regard to project type, location, environment, traffic volume, etc.

Tasks 5 and 6, completed in Year 2, utilized the information gained in Tasks 1 through 4 and address the implementation and training objectives. Task 5 entailed developing a training package for delivery to maintenance personnel in the TxDOT Districts. We prepared training materials consisting of presentations, a written instruction manual, and workbooks for each attendee. In Task 6, we delivered a pilot training session to senior maintenance personnel, and then provided a series of eight regional half-day training workshops, both face-to-face and by video teleconference, to over 550 maintenance personnel across the State. TxDOT videotaped one of the training sessions and VHS cassettes of the training were provided to each maintenance section.
Task 7 consisted of writing the project reports: (1) a 900-page Research Report in two volumes summarizing the work done in Tasks 1 through 4 and which is the principal document for our findings, and (2) a Training Report which summarizes the training and implementation aspects of the project.

\section{What We Found...}

The objectives for this research - to identify and to effectively communicate best practices for pavement edge maintenance - were accomplished by capturing over 3700 years of institutional knowledge from maintenance leaders representing all 25 Districts of TxDOT. The research focused on naturally occurring edge drop-offs with an emphasis on low-volume roads.

Identification of edge drop-offs is a key conceptual issue. Maintenance personnel tend to talk about edge dropoffs in risk-based terms with respect to two functional criteria: 1) the impact on safety of the traveling public, and 2) the potential for damage to the road (see Figure 2). In both cases, most maintenance supervisors rely primarily on their judgment as opposed to a levelof-service (LOS) definition, and cite the complexity of the issue when doing so. Of course, the TxDOT Maintenance Manual provides a LOS definition - it is desirable to maintain drop-offs at 2 inches or less, but it is acceptable and tolerable to maintain drop-offs at 3 inches or less. Maintenance personnel

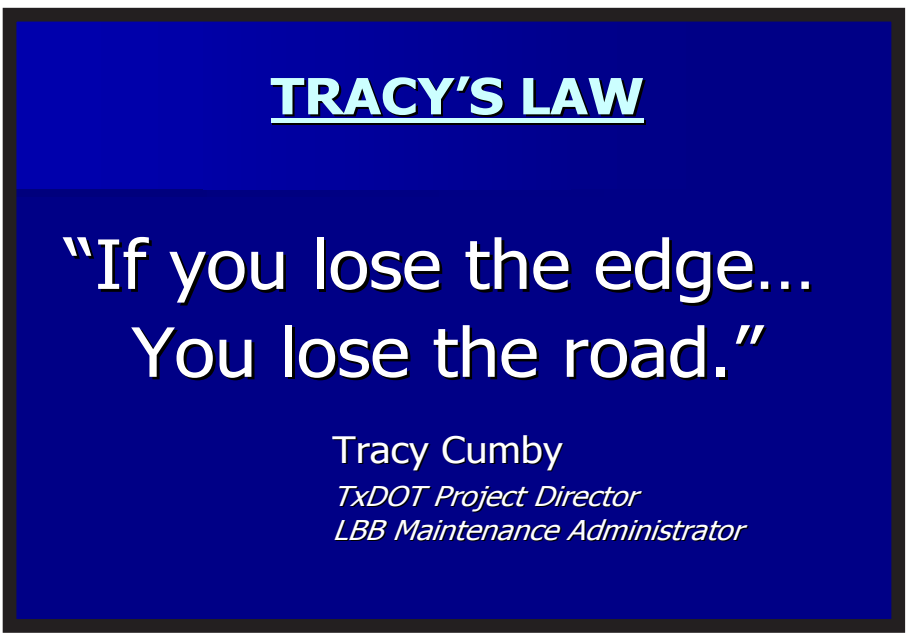

Figure 3. Tracy's Law points out that without good edge maintenance strategy, a District cannot achieve good roads. 


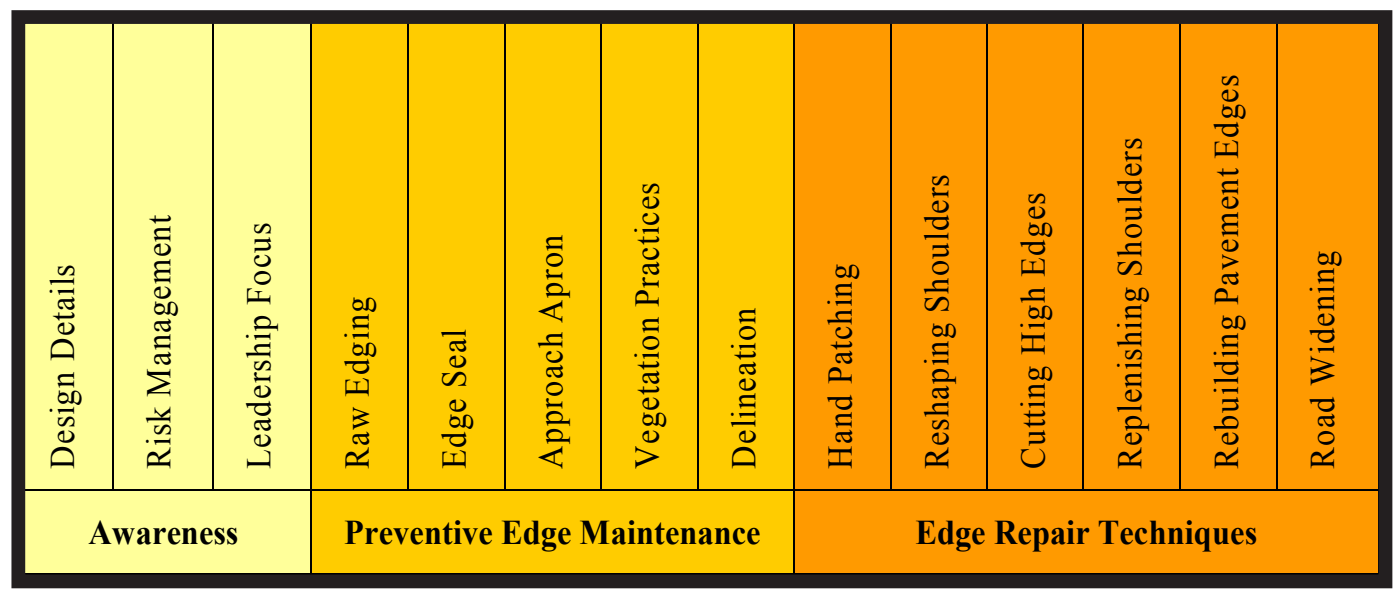

Figure 4. Edge maintenance practices and procedures fall into three broad categories: awareness, preventive maintenance, and edge repair techniques.

are responsible for both of these approaches.

The key factors causing edge drop-offs are narrow road width/absence of shoulders, traffic volume/type, and adverse environmental conditions. Tracy's Law, "If you lose the edge, you lose the road," provides a key perspective on meeting these challenges and points out that good edge maintenance strategy is not only important in achieving good

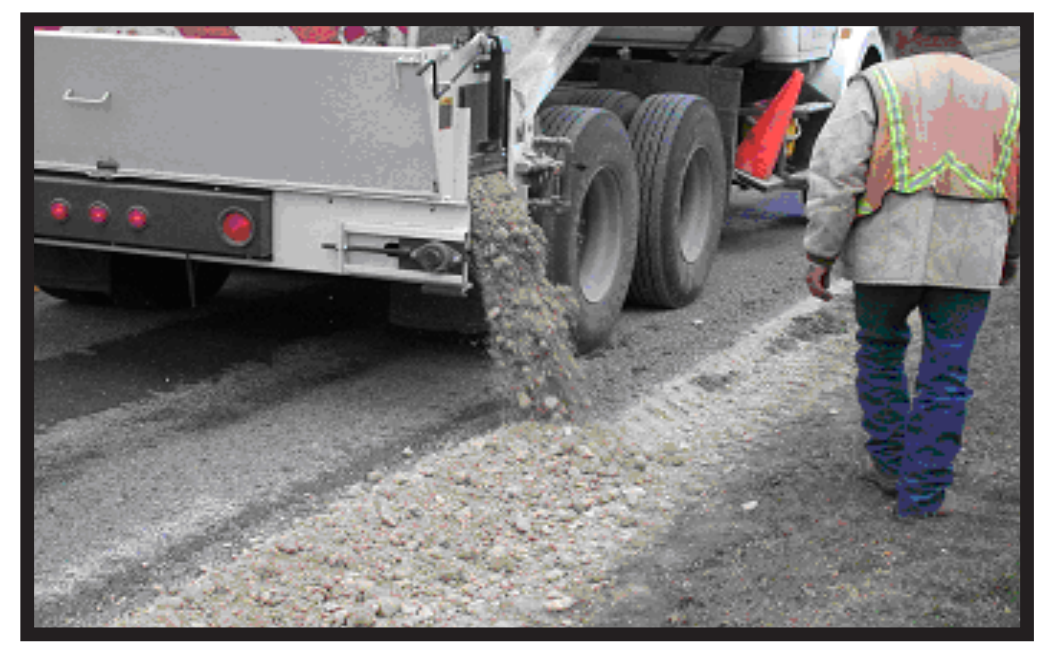

Figure 5. Edge maintenance equipment includes conventional, inhouse-modified, and commercially manufactured equipment specifically dealing with pavement edge drop-offs.

roads, but without good edge maintenance, a District cannot achieve good roads (see Figure 3).

Edge maintenance practices and procedures fall into three broad categories: awareness, preventive maintenance, and edge repair techniques (see Figure 4). Road widening - both in-house using TxDOT forces and by formal contract - emerged as the 


\section{For More Details...}

The research is documented in the following:

Report No. TX/03/4396-1: Research Report, Best Practices for Pavement Edge Maintenance, by William D. Lawson, P.E., and M. Shabbir Hossain, Ph.D., P.E., November 2003.

Report No. TX/03/4396-2: Training Manual, Best Practices for Pavement Edge Maintenance, by William D. Lawson, P.E., January 2003

Product No. TX/03/4396-P2: Best Practices for Pavement Edge Maintenance, District Survey, by William D. Lawson, P.E., and M. Shabbir Hossain, Ph.D., P.E., November 2003.

Research Supervisor: William D. Lawson, P.E., Senior Research Associate, TechMRT, (806) 742-3521.

Project Director: Tracy Cumby, District Maintenance Administrator, Lubbock District, (806) 748-4445.

To obtain copies of the reports, contact the Center for Transportation Research Library at (512) 232-3128, email ctrlib@utx.cc.utexas.edu.

\section{TXDOT IMPLEMENTATION STATUS May 2004...}

The findings of this project were implemented through training seminars taught by the researchers of this project throughout the state during the research project. Additional training has been provided through the training videos distributed to all TxDOT Districts. Future training seminars may be included in the Human Resources Division program or an implementation project.

For more information, contact; Dr. German Claros, P.E., Research and Technology Implementation Office, (512) 465-7403,gclaros@dot.state.tx.us.

\section{Your Involvement Is Welcome...}

\section{Disclaimer}

This research was performed in cooperation with the Texas Department of Transportation and the U.S. Department of Transportation, Federal Highway Administration. The contents of this report reflect the views of the authors, who are responsible for the facts and accuracy of the data presented herein. The contents do not necessarily reflect the official view or policies of the FHWA or TxDOT. This report does not constitute a standard, specification, or regulation, nor is it intended for construction, bidding, or permit purposes. Trade names were used solely for information and not for product endorsement.

The University of Texas at Austin

Center for Transportation Research Library

3208 Red River \#115

Austin, TX 78705-2650 